\title{
Effect of Polysaccharide Capsule of the Microalgae Staurastrum iversenii var. americanum on Diffusion of Charged and Uncharged Molecules, using EPR Technique
}

\author{
Cristina S. Freire-Nordi ${ }^{1}$, Armando A. H. Vieira ${ }^{2}$, Clovis R. Nakaie ${ }^{3}$, and Otaciro R. Nascimento ${ }^{1}$ \\ ${ }^{1}$ Departamento de Física e Informática, Instituto de Física de São Carlos/USP, \\ CEP 13.560-970, Cx. Postal. 369, São Carlos, SP, Brazil \\ ${ }^{2}$ Departamento de Botânica, Universidade Federal de São Carlos, 13565-905, São Carlos, SP, Brazil and \\ ${ }^{3}$ Departamento de Biofísica, Universidade Federal de São Paulo, 04044-020, SP, Brazil
}

Received on 29 August, 2005; accepted on 14 November, 2005

\begin{abstract}
The existence of a mucilaginous envelope, sheath or capsule is usual in many desmids, but few data concerning its function are available. Previous studies of the transport function and permeation of molecules through the algae capsules were done using the algae Spondylosium panduriforme and Nephrocytium lunatum, the Electron Paramagnetic Resonance (EPR) technique, and different spin labels. The results suggested that the capsule functions as a selective diffusion medium. In the present work charged and uncharged molecules (spin labels group $A$ ) and Staurastrum iversenii var. americanum (Desmids), whose alga presents a great mucilaginous capsule, were used. Charged nitroxide molecules similar to amino acids (spin labels group B) were also used allowing a better understanding of the electrostatic effect in the permeation process across the capsule. The role of the cell capsule in the solute diffusion was evaluated by determining the capsulated and decapsulated cell permeation times. The permeation times for all spin labels tested in the cells lacking capsules were always shorter than those containing this physical barrier. The decay times of spin labels group A observed for $S$. iversenii were compared to other studied algae. The results regarding the diffusion of charged spin labels group B suggested that the interaction of cell capsule occurs more strongly with negatively charged molecules than with positively charged ones. The results obtained in this work with spin labels group A confirm that the capsule is an essential structure for the cell, and that due to the polar interactions with the spin labels, it plays an important role in the selection of small molecules. Several parameters, mainly those of electrostatic nature, seem to control the permeation across the algal capsules of spin labels group $B$, showing that structures which are similar to amino acids could diffuse across the interior of the algal cell.
\end{abstract}

Keywords: EPR; Algae capsules

\section{INTRODUCTION}

Many microalgae species may accumulate extracellular polysaccharides, such as a gelatinous mass enclosing their cells, which are called envelopes, sheaths or capsules. These structures are easily found in many cocoid, monoid and filamentous Chlorophyta, mainly among the Desmidiales. However, studies concerning their functions, properties, and structures are still incipient.

In vivo EPR has become one of the most useful experimental techniques through which one can follow the metabolism of nitroxides in vivo [1-3]. Newer capabilities, which include the measurement of oxygen concentration, diffusion, viability, and temperature, have been developed in the last few years. Many investigators as Calvin et al. [4], Schara et al. [5] and Kveder et al. [6] observed a gradual intensity decrease of the EPR signal in cellular systems, presumably due to nitroxide reactions. This bio reduction changes according to the type of cell and depends on different factors such as the nitroxide structure, temperature, metabolic state of the cell, and oxygen concentration. Such reduction mostly occurs inside the cells, but the mechanism is not fully established.

Capsules demand photosynthetic energy from the algal cell for their building and maintenance [7] and, consequently, play a fundamental role in the interaction between the cells and their environment $[8,9]$. Considering that the function of the algal capsule in working as a barrier on the transport and permeation of molecules into the cell is important, the EPR technique and a variety of different spin labels, functioning as probe molecules, were used so as to demonstrate it. The EPR technique consists in measuring how long it takes for the spin labels to go through the capsule, the cell wall and the plasmatic membrane, and later be destroyed by metabolic processes in the interior of the cell, where they lose their paramagnetic properties.

A preliminary study was conducted by using the desmid Spondylosium panduriforme (Heimerl) Teiling [10], the EPR technique, and different spin labels (with different molecular structures and polar fragments) as probes. This filamentous alga has a great and continuous capsule involving the entire filament. A second study was conducted, and similarly to the first one, used the same spin labels but a different microalga, the chlorococcales Nephrocytium lunatum West [11]. This colonial alga has the cells ( 2 to 4 ) immersed in a gelatinous mass. The data obtained from both works indicate that the capsules, as a result of electrostatic polar interactions between their structure and the spin labels, may play a selective role. Another interesting remark found in the two other studies concerns spin label IV, the only one that is charged and whose characteristic permeation times behaviour is different from the other spin labels, suggesting that the polysac- 
charide capsule probably tends to interact more strongly with the charged molecules than with the non-charged ones.

Although both studies clearly evidence the capsule selective function, data are still inconclusive for a broader conclusion to be drawn. A different alga Staurastrum iversenii Nygaard var. americanum was used in the present work so as to gain further information. Although belonging to the same group as $S$. panduriforme, this desmid is unicellular, and has a big, rigid and well-defined capsule. The EPR technique and the spin labels previously mentioned were used, and a new class of spin labels consisting of molecules similar to amino acids and having different charged groups, was introduced in order to obtain additional detailed data about the transport and permeation of charged molecules. The resulting permeation data will be compared to those previously acquired, and the observed differences will be related to structure and conformation of the capsular polysaccharides. The reason why amino acid spin labels have been introduced is also to verify the diffusion of this important biological class of molecules across the algal cells.

\section{METHODS}

\section{A. Algae cultivation conditions}

Staurastrum iversenii var. americanum was isolated from Barra Bonita Reservoir, São Paulo State, Brazil and kept in the culture collection of the Botany Department of the Federal University of São Carlos as chain BB-024.

The algae grew in bath culture in a $4 \mathrm{~L}$ glass carboy using WC medium [12] under axenic conditions. Cultures were incubated at temperatures ranging from 21 to $23{ }^{\circ} \mathrm{C}$ using fluorescent light $\left(174 \mu \mathrm{mol}\right.$ photons. $\left.\mathrm{m}^{-2} . \mathrm{s}^{-1}\right)$, light/dark cycle of 12:12 hours and continuous aeration by gentle bubbling with filtered air. The $\mathrm{pH}$ medium of algal preparation was adjusted between 6.5 and 7.0 .

\section{B. Algal Cells and Electron Paramagnetic Resonance measurements}

Growth curves for the algae were obtained in duplicate and it was observed that after a period of 30 days the stationary phase had been reached and, therefore, the cells were in an ideal condition to be measured. The culture was terminated, the supernatant was decanted, and the algal cells were firstly centrifuged for 10 minutes at 3,000 rpm in a FANEM Exelsa Baby II centrifuge, and secondly centrifuged in a Eppendorf Spin I (Incibras) centrifuge, in order to remove the remaining culture medium. From this concentrated suspension of cells, $50 \mu \mathrm{L}$ were taken and kept in Eppendorf vials, for EPR measurements. No modification on EPR spectrum was observed, either when an aliquot of the remaining culture medium was tested with spin labels, or when the algal cells were killed with sodium azide (5\%), washed with WC medium and tested with spin labels.
Some of the algal cells had their capsules removed by Ultrasound to check the contributions of the cell wall, the cellular membrane and the metabolisation time in the cytosol. This treatment was conducted using a Branson 450 Sonifier sonicator at a 10-Watt intensity, applied for one minute with 10second pulses at 1-second intervals. Many tests were carried out in order to remove the capsule, which was controlled by optical microscopy.

The measurements of the capsules thickness and cell size were obtained by optical microscopy, and by measuring 100 cells randomly chosen and stained with Indian ink, so as to make the capsules evident.

\section{Spin labels and EPR measurements}

In this study two groups of spin labels with different characteristics were used: "spin labels group A", composed of the same spin labels previously used, and "spin labels group B" composed of the charged nitroxide molecules similar to amino acids.

The used spin labels group A were: 2,2,6,6tetramethylpiperidine-1-oxyl (Tempo-I), the derivatives 4-hydroxy (Tempol-II), 4-piperidinone (Tempone-III), the charged 4-amino (Tempamine-IV); 2,2,4,4-tetramethyl-3hidroxi-5 -phenyl-1-imidazolinyloxyl (Imidazolyne-V) and the 3-maleimide-2,2,5,5-tetramehyl-1-pirrolidinloxyl (Maleimide-Proxyl-VI). The spin labels were all dissolved in ethanol and diluted in water resulting in a final concentration of around $200 \mu \mathrm{M}$. The charged spin labels group $B$ used, were: 2,2,5,5-tetramethylpyrrolidine-Noxyl-3-amino-4-carboxilic acid (VII); 2,2,2,5-tetramethyl1-pyrrolidine-N-oxyl-3-carboxilic acid (VIII); 2,2,2,5tetramethipyrrolidine-N-oxyl-3-amino-4-nitrile (IX); 2,2,6,6tetramethyppiperidine-N-oxyl-4-amino-4-carboxilic acid (X) and 3-amino- 2,2,2,5-tetramethylpyrrolidine-1-oxyl (XI). Spin labels VII and $\mathbf{X}$ were synthesized in a laboratory $[13,14]$ and dissolved in water to obtain the approximate concentration of $200 \mu \mathrm{M}$. Figures 1 and 2 show the molecular structures of spin labels group $A$ and group $B$.

These different spin labels were chosen not only because of their low probability of chemically reacting with polysaccharides and lipids that constitute the capsule, cell wall and membrane, but also because of their high probability of penetrating the interior of the cell.

The EPR spectra were measured in a Varian E-109 spectrometer in band $\mathrm{X}$, equipped with a rectangular cavity (E248) linked to a PC, and used a national instrument for data acquisition. The used spectra parameters were microwave power, $20 \mathrm{~mW}$; modulation frequency, $100 \mathrm{KHz}$; modulation amplitude, 1,25 G; magnetic field scan, $100 \mathrm{G}$; and detector time constant, $64 \mathrm{~ms}$. The spin label signal decay intensity was time-monitored, fixing the magnetic field up to the highest value of the EPR spectral central band. All EPR spectra out of four different spin labels were time-monitored in order to detect any spectral modifications and to test the environment influence on the diffusion dynamics across the different algal media. This kind of measurement permits to detect the 


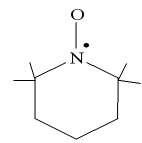

$\mathbf{I}$<smiles>CC1(C)CC(O)CC(C)(C)N1[O]</smiles>

II<smiles>CC1(C)CC([NH3+])CC(C)(C)[N+]1=O</smiles>

IV

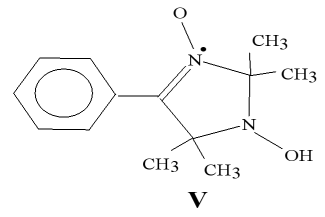

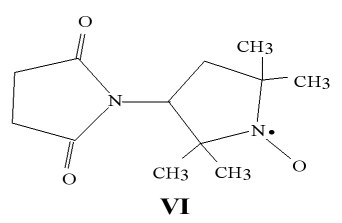

VI
FIG. 1: Molecular structures of spin labels group A: 2,2,6,6, tetramethylpiperidine-1-oxyl (I). The derivatives 4-hydroxy (II), 4 piperidinone (III), the charged 4-amino (IV), 2,2,4,4, -tetramethyl-3hydroxy-5-phenyl-1-imidazolinyloxyl (V) and 3-maleimide-2,2,5,5,tetramethyl-1pirrolinyloxyl (VI).

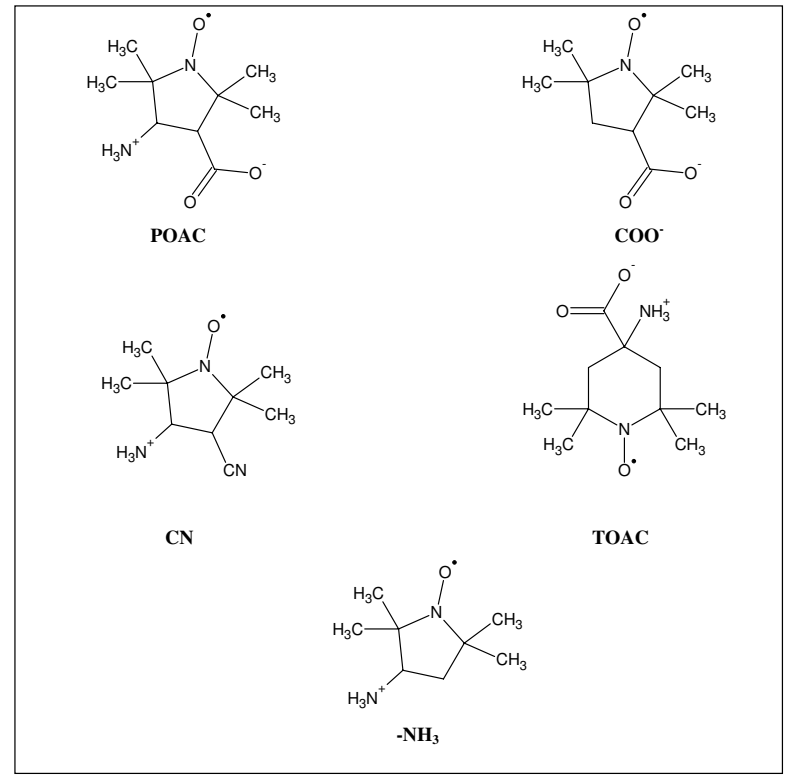

FIG. 2: Molecular structures of spin labels group B: 2,2,5,5, tetramethylpyrrolidine-N-oxyl-3-amino-4-carboxilic acid (VII); 2,2,5,5-tetramethylpyrrolidine-N-oxyl-3-carboxilic acid (VIII); 2,2,5,5-tetramethylpyrrolidine-N-oxyl-3-amino-4-nitrile (IX); 2,2,6,6-tetramethylpyrrolidine-N-oxyl-4-amino-4-carboxilic acid (X) e 2,2,5,5-tetramethylpyrrolidine-N-oxyl-3-amino (XI).

real possibility of chemical reaction between spin label and media fragments especially with spin label VI that could react with $\mathrm{SH}$ protein groups. It also permits to detect significant changes in the micro-viscosity of the different environments.

Figure 3 shows a general scheme of the experimental procedure used for obtaining decay curves for all spin labels. De- tails of the method are carefully described in Freire-Nordi et al. [10].

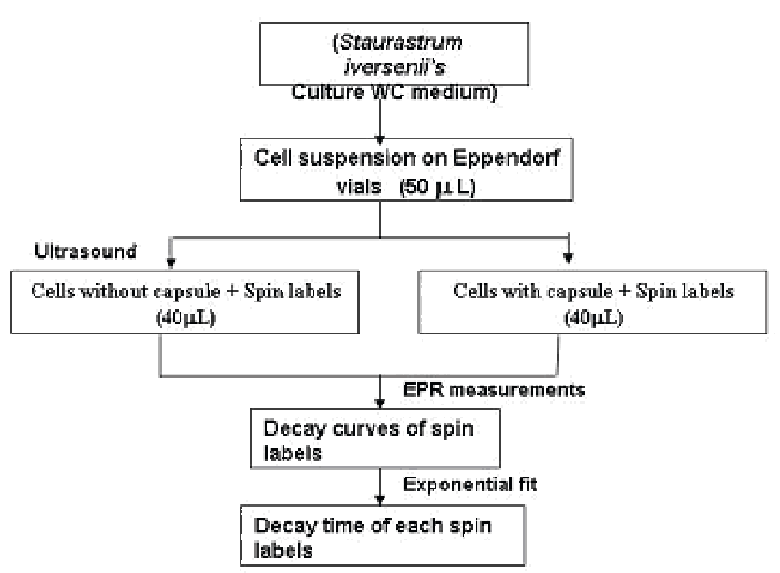

FIG. 3: Overall scheme of step-by-step experimental procedure showing the preparation and acquisition of the diffusion time with an integral algal cell and a decapsulated one.

\section{Polysaccharides composition}

To obtain the soluble extracellular polysaccharides in the culture medium (EPS) and the capsular polysaccharide (CPS), a culture was prepared under the same previously described conditions.

The culture medium containing EPS was obtained by decantation and tangential filtration, by using $0.65 \mu \mathrm{m}$ porosity cartridges (A/G Technology Corporation, Needham, MA, USA). The resulting culture medium was then dialyzed against distilled water in a Spectrapor dialysis tube (molecular weight cut off of 12,000-14,000) and freeze-dried until the analyses.

The alga cells separated from the medium were fixed with $5 \%$ formaline, and then centrifuged in a fresh culture medium to remove the formaline. The capsular material - CPS, was obtained by removing the capsules by means of progressive 4\% Dakin liquid washings and a 30-minute stir, at a temperature of $40{ }^{\circ} \mathrm{C}$. Using an optical microscope, we could observe the cells and control the removal of the capsules, after which the cells were eliminated by centrifugation, and the medium containing CPS was dialyzed and freeze-dried until analyses.

Identification and quantification of monosaccharides present in EPS and CPS were obtained by gas chromatography, after methanolysis of freeze-dried samples. The samples were prepared following the methods proposed by [15] and [16].

The amount of the protein in the EPS and CPS was determined according to [17] and the sulfur content using a CHNS Automatic Elemental Analyser (EA 1110 Carlo Erba). 


\section{RESULTS}

\section{A. Microalgae description}

The green microalgae Staurastrum iversenii Nygaard (1949) var. americanum belong to the order Desmidiales and class Zygnematophyceae. Their cells are rectangular. A constriction divides the cell in two triangular hemi cells, each containing two divergent apical processes, inserted at the opposite end to the isthmus. A $12 \mu \mathrm{m}$-thick mucilaginous sheath (Fig. 4) encloses the cell (including the processes). The algal cells are $17 \mu \mathrm{m}$ long, and each semi cell is $2 \mu \mathrm{m}$ wide.

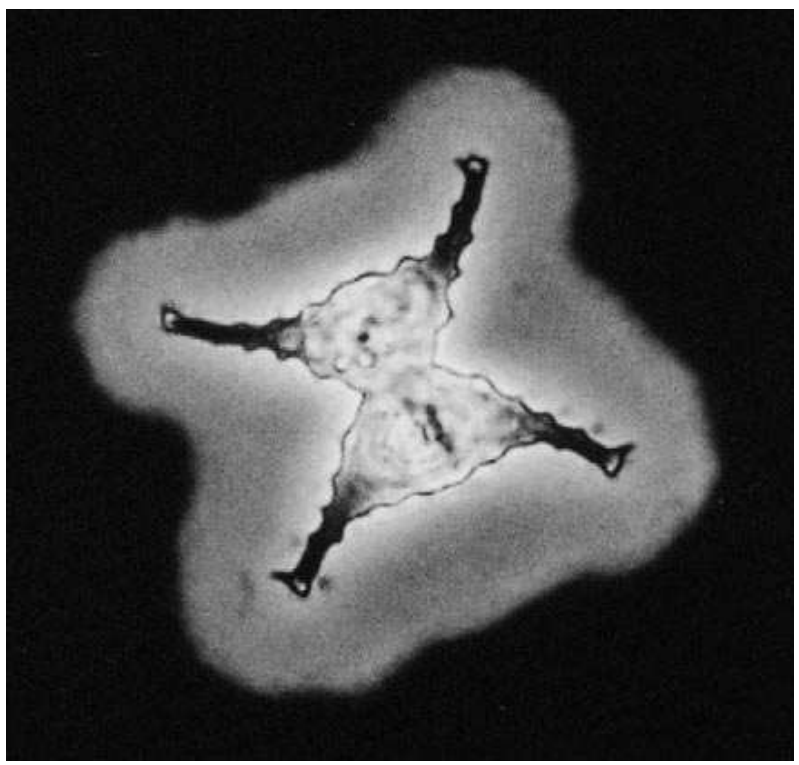

FIG. 4: Photomicrograph of Staurastrum iversenii cells stained with Indian ink showing the mucilaginous capsule surrounding the cell. Cell morphology details can also be seen.

\section{B. EPR data}

Figures 5A, 6A, 7A and 8A present the experimental characteristics of three-line EPR spectra decays for spin label molecules group A: III (polar), IV (positively charged) and VI (chemical reaction possibility), and spin label molecules group B VII (negatively charged). These sequential spectra decays result from their diffusion across the algal cells to the cytoplasm medium where the cell metabolism destroys the paramagnetic properties of the spin label fragment. The selection of these four spin labels was performed considering the big difference between the decay time, charge character and chemical reaction possibility. A comparison among figures 5A, 6A, 7A and 8A reveals four different decay patterns: the fastest decay (Fig. 5A), the least fast one (Fig.6A), the least slow decay (Fig.7A) and the slowest one (Fig. 8A). Figures $5 \mathrm{~B}, 6 \mathrm{~B}, 7 \mathrm{~B}$ and $8 \mathrm{~B}$ show three EPR spectra at three different times taken from Figures 5A, 6A, 7A and 8A, so that the spectra details can be clearly seen. No changes, such as broad- ening of the line width, or modifications in the intensities between the three lines, or a new superimposed spectrum [18] were observed on the spectral form. All different spin labels used behaved similarly, i.e., presented no spectral changes. This clearly indicates that the only phenomenon observed is the variation of peak-to-peak intensity of the spectra due to the cell metabolism. As a result of diffusion throughout the algal media, the paramagnetic property of the spin label fragment is destroyed in the cytosol.

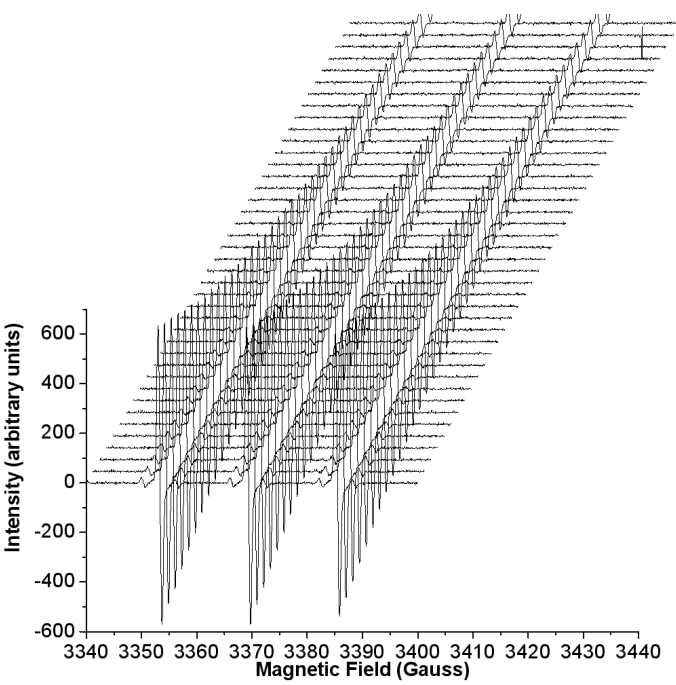

A

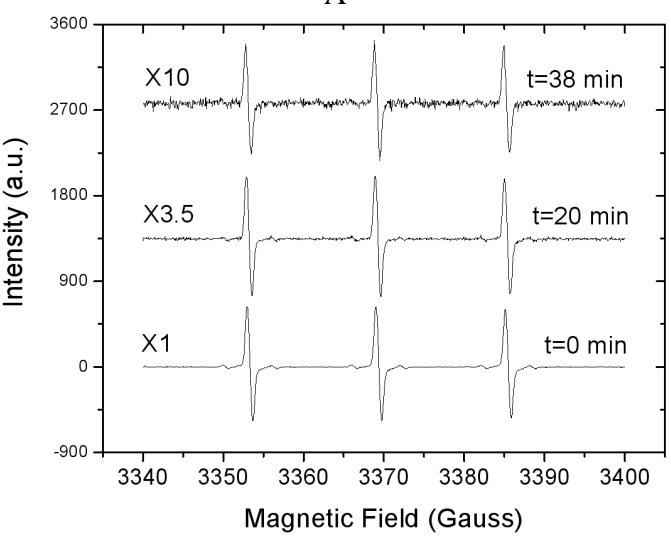

B

FIG. 5: The three-line spectra of spin label III (5A) shows the decaytime intensity decrease. The measurements were taken at 2-minute intervals, while the spin labels were crossing the algae capsule. Details of EPR spectra of spin label III (5B) at three different diffusion times clearly visualizing the absence of any spectral differences.

Figure 9 shows the experimental intensity-time graph of the paramagnetic signal for spin label group B-IX (A) used with entire algal cell, and spin label group A-VI used with entire cell (B) and decapsulated one (C). The best exponential fit of all curves is showed as a continuous line and was used to obtain the decay times. The position of the correspondent intensity of decay half-time is represented in curve C. Spin label VI decay time curve for decapsulated cells (C) falls to zero faster than the capsulated ones (B). By comparing the curves 


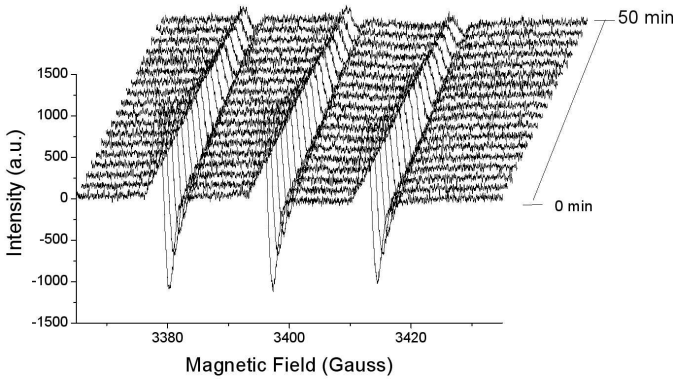

A

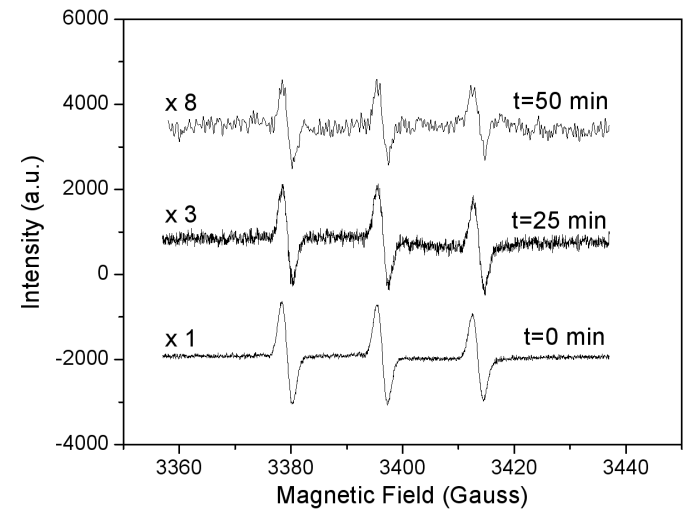

B

FIG. 6: The three-line spectra of spin label IV (6A) shows the decaytime intensity decrease. The measurements were taken at 2-minute intervals, while the spin labels were crossing the algae capsule. Details of EPR spectra of spin label IV (6B) at three different diffusion times clearly visualizing the absence of any spectral differences.

for integral cells it can be seen that spin label group A-VI (B) permeation time is faster than spin label group B-IX (A).

The results of decay times for spin labels group $A$ are shown in Table 1. In addition, the equivalent decay times obtained for S. panduriforme [10] and Nephrocytium lunatum [11] are also shown to make the comparisons clearer. Table 2 shows the decay times obtained from spin labels group $B$.

In these two tables, $\mathbf{T 1}$ represents the decay times for the entire alga, i.e., with the capsule; $\mathbf{T} 2$ the decay times for the cells without capsules; and the characteristic permeation times through the capsule, $\Delta \mathbf{T}$, that corresponds to T1-T2. The average of at least three measurements is followed, in brackets, by its correspondent standard deviation.

The characteristic permeation times of the cells without capsule (T2) were always shorter than the ones obtained for capsular cells (T1) in both spin label groups studied, proving that the polysaccharide capsule plays an important role as a resistant medium to the diffusion mechanism. Furthermore, no spin labels bond was found in the polysaccharide capsule.

The sequence of characteristic permeation times for spin labels group $A$ (Table 1 ) was: $\mathbf{V}<$ I $<$ VI $<$ II $<$ IV $<$ III for the cells without capsule, and $\mathbf{V}<$ I $<$ II $<$ III $<$ IV $<$ VI for the capsulated cells, respectively, considering the last sequence as the longest one. The observed sequence for decay times through the capsule alone, $\Delta \mathbf{T}$, was the same as for $\mathbf{T 1}$.

For spin labels group B (Table 2), the order of decay times

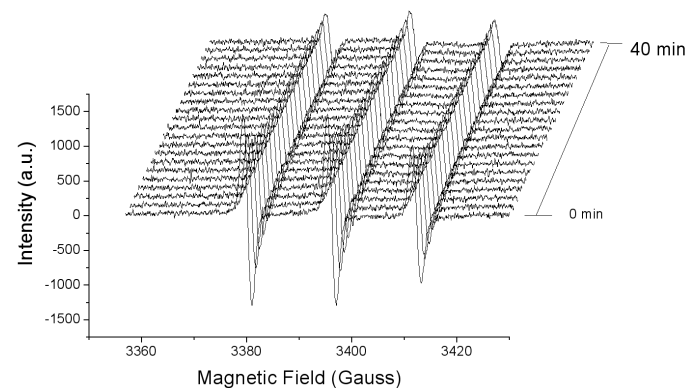

A

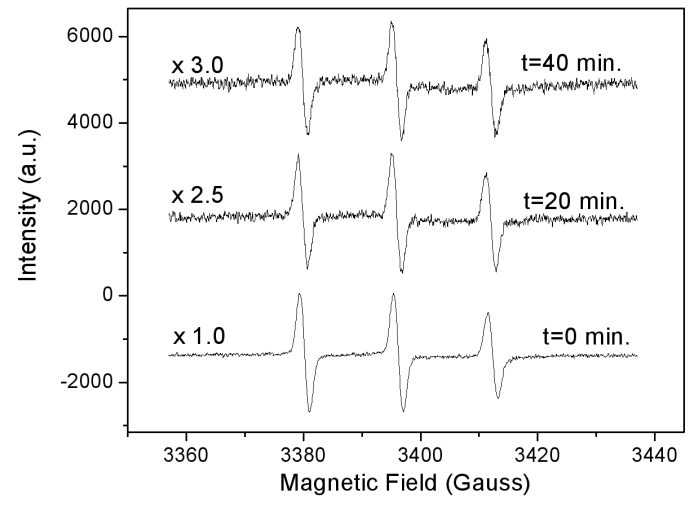

B

FIG. 7: The three-line spectra of spin label VI (7A) shows the decaytime intensity decrease. The measurements were taken at 2-minute intervals, while the spin labels were crossing the algae capsule. Details of EPR spectra of spin label VI (7B) at three different diffusion times clearly visualizing the absence of any spectral differences.

in capsulated and decapsulated cells was: VII $<\mathbf{X}<\mathbf{X I}<$ $\mathbf{I X}<\mathbf{X}$ and $\mathbf{X} \cong \mathbf{V I I} \cong \mathbf{I X}<\mathbf{X I} \cong \mathbf{X}$, respectively.

The characteristic permeation times of spin labels group $A$ (Table 1) are shorter than spin labels group $B$ (Table 2), revealing the charge effect of aminoacid spin labels.

Tests have been performed in order to determine the dependence of extracellular oxygen on the nitroxides reduction rate. Tests involved the presence of excess (bubbling oxygen for 5 minutes) and absence of oxygen (bubbling nitrogen for 5 minutes). The results showed that the external oxygen practically did not interfere in the nitroxides reduction process (Table 3). The decay times are the same considering the experimental standard deviation.

\section{Monosaccharide composition}

Table 4 shows the composition of monosaccharides present in the capsular material (CPS) and in the dissolved medium (EPS). The composition of the sugars present in CPS and EPS consists of fucose, galactose, rhamnose and xylose monosaccharides. In both polysaccharides, galactose and fucose are the dominant monosaccharides and totalise around $80 \%$.

No sulfate was detected in any of the polysaccharides, CPS and EPS. The protein content was $5.6 \%$ in CPS and 
TABLE I: Decay time of the EPR signal and molecular weight of the spin label group A used in the study with the algae: Staurastrum iversenii and the others algae studied Spondylosium panduriforme. (Freire-Nordi et al., 1998) and Nephrocytium. lunatum (Freire-Nordi et al., 2003. The numbers inside the brackets represent the standard deviation of the measurements (at least three measurements). $\boldsymbol{T}_{1}$ : the permeation time across the capsule, cell wall and membrane; $\boldsymbol{T}_{2}$ : the permeation time across the cell wall and membrane for the cells without capsule; $\Delta \boldsymbol{T}:$ the permeation time only across the capsule $\left(\mathbf{T}_{1}-\mathbf{T}_{2}\right)$.

\begin{tabular}{|c|c|c|c|c|c|c|c|c|c|c|}
\hline & & $\boldsymbol{T}_{1}(\mathrm{~min})$ & & & $\boldsymbol{T}_{2}(\min )$ & & & $\Delta \boldsymbol{T}(\min )$ & & \\
\hline $\begin{array}{l}\text { Spin } \\
\text { Label }\end{array}$ & $\begin{array}{l}\text { MW } \\
(\mathrm{g})\end{array}$ & $\begin{array}{l}\text { S. panduri- } \\
\text { forme }\end{array}$ & N. lunatum & S. iversenii & $\begin{array}{l}\text { S. panduri- } \\
\text { forme }\end{array}$ & N. lunatum & S. iversenii & $\begin{array}{l}\text { S. panduri- } \\
\text { forme }\end{array}$ & N. lunatum & S. iversenii \\
\hline I & 156 & $3.12(0.18)$ & $2.15(0.3)$ & $4.18(0.1)$ & $1.47(0.2)$ & $1.15(0.05)$ & $1.76(0.2)$ & 1.65 & 1.00 & 3.07 \\
\hline II & 172 & $4.77(0.33)$ & $3.17(0.2)$ & $12.21(0.6)$ & $2.55(0.7)$ & $1.61(0.20)$ & $7.92(1.0)$ & 2.22 & 1.56 & 4.29 \\
\hline III & 170 & $6.01(0.51)$ & $4.78(0.2)$ & $18.51(2.1)$ & $1.12(0.2)$ & $1.05(0.34)$ & $10.17(0.4)$ & 4.89 & 3.73 & 8.34 \\
\hline IV & 170 & $\infty$ & $14.28(4.6)$ & $23.03(0.7)$ & $8.78(0.6)$ & $3.89(0.62)$ & $8.59(0.9)$ & $\infty$ & 10.30 & 14.44 \\
\hline $\mathbf{V}$ & 213 & $1.64(0.28)$ & $1.75(0.4)$ & $2.73(0.3)$ & $0.80(0.1)$ & $0.80(0.10)$ & $1.46(0.3)$ & 0.84 & 0.95 & 1.28 \\
\hline VI & 236 & $\infty$ & \begin{tabular}{|l|}
$\infty$ \\
\end{tabular} & $43,35(9,7)$ & $\infty$ & $\infty$ & $3,24(0.6)$ & $\infty$ & $\infty$ & 40,11 \\
\hline
\end{tabular}

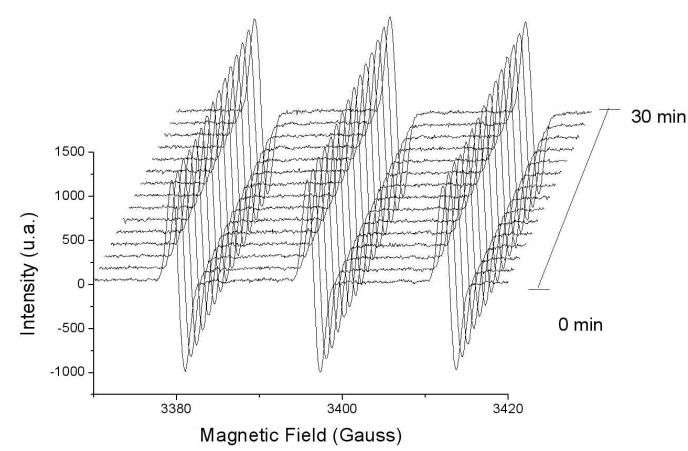

A

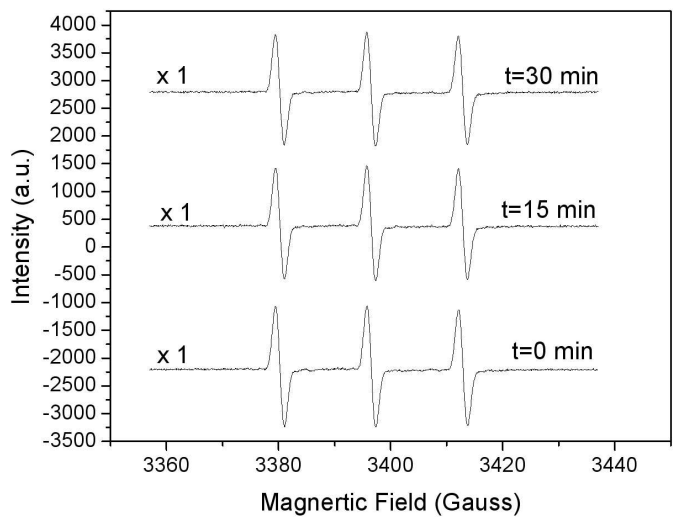

B

FIG. 8: The three-line spectra of spin label VIII (8A) shows the decaytime intensity decrease. The measurements were taken at 2minute intervals, while the spin labels were crossing the algae capsule. Details of EPR spectra of spin label VIII (8B) at three different diffusion times clearly visualizing the absence of any spectral differences.

\section{$13.3 \%$ in EPS.}

\section{DISCUSSION}

Spin labels group A I, II, III and IV have very similar molecular weights, but differ with respect to the groups presented

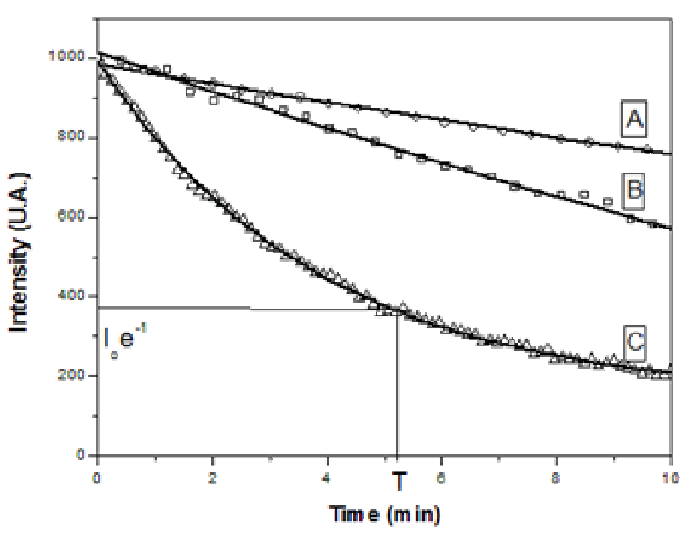

FIG. 9: A- Decay time curve of spin label group $B$-IX obtained with encapsulated algal cells; B- Decay time curve of spin label group AVI, used with encapsulated algal cells, and C- Decay time curve of the same spin label group A- VI, used with decapsulated algal cells.

TABLE II: Decay time of the EPR signal and molecular weight of the spin label group B used in the study with the algae Staurastrum iversenii. The numbers inside the brackets represent the standard deviation of the measurements (at least three measurements). $T_{1}$ : the permeation time across the capsule, cell wall and membrane; $T_{2}$ : the permeation time across the cell wall and membrane for the cells without capsule; $\Delta T$ : the permeation time only across the capsule $\left(\mathbf{T}_{1}-\mathbf{T}_{2}\right)$.

\begin{tabular}{ccccc}
\hline Spin Label & $M W(g)$ & $\boldsymbol{T}_{1}(\mathrm{~min})$ & $\boldsymbol{T}_{2}(\mathrm{~min})$ & $\Delta \boldsymbol{T}(\mathrm{min})$ \\
\hline TOAC & 215 & $139,19(37,59)$ & $18,89(1,94)$ & 120,30 \\
\hline POAC & 199 & $251,61(60,14)$ & $32.72(0.95)$ & 218,89 \\
\hline $\mathbf{N H}_{3}^{+}$ & 155 & $401,76(21,61)$ & $18,47(5,45)$ & 383,29 \\
\hline $\mathbf{C O O}^{-}$ & 182 & $\infty$ & $32.10(6.1)$ & $\infty$ \\
\hline $\mathbf{C N}$ & 181 & $190,26(7,95)$ & $32,11(2,75)$ & 158,15 \\
\hline
\end{tabular}

in their structures $\left(-\mathrm{O},-\mathrm{OH},=\mathrm{O}\right.$ and $\left.\mathrm{NH}^{+}\right)$. Therefore, the decay time sequence obtained from $T_{1}$ and $\Delta T$ can be related to the strength of the hydrogen bond between the $-\mathrm{OH}$ groups in the capsule structures, and the different groups of these spin labels. Since the capsules of this alga have proteins in their structures, it is also reasonable to consider the pos- 
TABLE III: Reduction time of nitroxide spin label I with Staurastrum inversenii cells in the air, $100 \%$ Nitrogen- $\mathrm{N}_{2}$ (absence of oxygen by bubbling nitrogen for 5 minutes) and $100 \%$ Oxygen- $\mathrm{O}_{2}$ (by bubbling oxygen for 5 minutes).

\begin{tabular}{|c|c|}
\hline & Reduction time (min) \\
\hline Air & $2.38(0.6)$ \\
\hline $\mathrm{N}_{2}$ & $2.52(0.6)$ \\
\hline $\mathrm{O}_{2}$ & $2.48(0.5)$ \\
\hline
\end{tabular}

TABLE IV: Relative monosaccharide composition of the CPS and EPS produced by the algae Staurastrum iversenii, determined as the TMSi derivatives of the corresponding methyl-glycosides. The data are presented as a medium value of two measurements \pm standadard deviation.

\begin{tabular}{|l|l|l|}
\hline Alga & \multicolumn{2}{|l|}{ Staurastrum iversenii } \\
\hline Monosaccharide & CPS (mol\%) & EPS (mol\%) \\
\hline Xylose & $9,18 \pm 0,53$ & $10.11 \pm 0.29$ \\
\hline Rhamnose & $7.6 \pm 1.58$ & $10.03 \pm 4.20$ \\
\hline Galactose & $40,20 \pm 0,37$ & $40.19 \pm 2.19$ \\
\hline Fucose & $43.03 \pm 0.84$ & $42.86 \pm 1.08$ \\
\hline
\end{tabular}

sibility of electrostatic interactions between spin labels and protein fragments of algal capsules.

The comparison among spin label decay times observed for $S$. iversenii and the two other algae studied S. panduriforme [10] and N. lunatum [11], revealed similarities and differences. From Table 1, the sequence of decay times for the three algal species for ( $T_{1}$ and $\Delta T$, for encapsulated cells is the same $(\mathbf{V}<$ I $<$ II $<$ III). Nevertheless, the values of the decay times are quite different among the three algae, being $S$. iversenii the longest one. Such differences could be related to the following aspects: different routes through the capsules according to the size of the capsule for the spin label trajectory, different monosaccharide composition of the three algal capsules $[10,11]$, and compactness of the polysaccharide capsules. The average distance travelled by the spin labels is most likely shorter in $N$. lunatum compared to $S$. panduriforme, what would explain their shorter decay times. When compared to the two other algae, the cells of $S$. iversenii are the smallest, and so is their capsules thickness, making it difficult to compare and explain the differences concerning the dimensions of the alga capsule alone. Considering the monosaccharide composition, $S$. iversenii presented the highest content of deoxy sugars giving its capsules a more hydrophobic nature, what could explain their higher characteristic permeation times.

The greatest differences observed among the three algae concern spin labels IV and VI. Spin label IV, which has a net charge $\left(-\mathrm{NH}^{+}\right)$at physiological $\mathrm{pH}$, did not permeate across the $S$. panduriforme capsule, but it crossed the $S$. iversenii and $N$. lunatum capsules. Spin label VI presented the longest characteristic permeation time through the $S$. iversenii capsule, what was completely different from that obtained for the algae, S. panduriforme and N. lunatum, where such spin label did not penetrate the cells. The monosaccharide composition and compactness can explain the different behaviours of spin labels IV and VI among the different algae. However, a better characterization of the polysaccharide compactness is needed and can be obtained by algae capsule electron micrography, which will be carried out in the near future. Moreover, it must be taken into account that spin label VI does not penetrate $S$. panduriforme and $N$. lunatum even when the capsule is removed. On the contrary, the $S$. iversenii capsule removal greatly facilitates the diffusion across this cell (see decay time Table 1). These results suggest that the cell wall and membrane could be the main barrier for spin label VI permeation through $S$. panduriforme and $N$. lunatum cells other than the capsules.

The measured order of decay times in capsulated cells of charged spin labels group B clearly depicted an electrostatic effect in the diffusion process of these amino acid cyclic molecules. The observed difference on permeation velocity of these spin labels showed that the more negative the character of the charged molecule, the stronger its interaction with the cell capsule is. This assertion was easily observed mainly for the most negatively charged spin probe (VIII). On the other hand, spin label $\mathbf{X}$ displayed faster permeation than its VII partner. Both of them have amine and carboxyl functional groups (Fig. 2), but they are differently attached to the pyrrolidine cyclic structure. In spin label $\mathbf{X}$ they are attached to the same carbon $\left(\mathrm{C}_{4}\right)$, but in spin label VII to different carbons ( $\mathrm{C}_{3}$ and $\mathrm{C}_{4}$ atoms). Such great proximity could provide a more intense electrostatic interaction between them leading to an internal self-neutralizing effect of both groups in the molecule (spin label $\mathbf{X}$ ), causing a less intense interaction and a faster diffusion through this structure. This effect can be probably smaller in spin label VII due to a longer distance between the carboxyl and amine groups, and a more intense interaction with capsule moiety. Additional and more acceptable explanations for these findings would possibly be achieved by the determination of the ionisation constant of both amine and carboxyl functions of all spin labels studied. However, so far only spin label $\mathbf{X}$ has had its two functional groups potentiometrically determined, showing $\mathrm{pKa}$ values of 8 and 2 for the amine and carboxyl groups, respectively [13].

The behaviour of decapsulated cells, whose characteristic permeation times are shorter than the capsulated cells, is similar to that observed with spin labels group A.

The capsule removal might cause changes in the oxygen availability, shifting the algal metabolic status, and changing the probe reduction spin rate that could be the reason for these results. Most available data are consistent, mainly using mammalian cells, with a main reduction site occurring in the electron transport chain of the mitochondria at the ubiquinone level, and the nitroxides reduction products being the corresponding hidroxylamines $[19,20]$. Thus, the nitroxides reduction and hydroxylamines oxidation by cells have been proved to be highly dependent on the oxygen concentration [21].

The presence of photosynthetic reactions provides both an additional tool and a source of increased complexity in the nitroxides reduction process. In the first report on the nitroxides reduction by a viable biological photosynthetic system, one algal species was used [22], and it was shown that such reduction was associated with a photochemical process and the reduction tentatively was attributed to plastoquinone 
semiquinone. Similar reduction was observed in spinach leaf chloroplasts by Weaver [23]. Regarding such aspect, our results also showed that the external oxygen presented low influence on the nitroxides reduction, therefore, contrasting with the oxygen influence on intact mammalian cells. The behaviour of decapsulated cells with shorter permeation times than the capsulated ones can be due to the polysaccharide capsule alone, what confirms its role as a selective media.

\section{CONCLUSIONS}

The results obtained in this work with spin labels group $A$ and those observed in two different alga species, $S$. panduriforme [10] and N. lunatum [11], investigated by us, confirm that the capsule is an essential structure for the cell, and that, as a result of polar/electrostatic interactions with the spin labels, it plays an important role in the selection of small molecules.

Spin labels group B, which are also similar to amino acids, reveal that these kinds of molecules can permeate across algal capsules and supply the cells with these important classes of molecules, although the permeation times of such class of spin labels are slightly longer than those of class A. This is probably due to the fact that the interaction of such spin labels group with the structure of the capsule is stronger owing to the presence of liquid charges.

\section{Acknowledgments}

This work is specially dedicated to Prof. Dr. Horácio Panepucci who kindly shared his laboratory facilities with one of the authors during the first few years of work in Biophysicsrelated problems at the Instituto de Física de São Carlos, thus helping to consolidate such an area of research in our institute. We would like also to thank Brazilian Foundation FAPESP for financial support and specially the PhD student Luciana, who helped to synthesize some of charged molecules used in this work.

\section{Nomenclature:}

EPR - Electron Paramagnetic Resonance

CPS - Capsular Polymeric Substance

EPS - Extracellular Polymeric Substances

\section{Spin labels}

I- spin label group A Tempo

II- spin label group A Tempol

III- spin label group A Tempone

IV- spin label group A Tempamine

V- spin label group A Imidazolyne

VI- spin label group A Maleimide-Proxyl

VII- spin label group B 2,2,5,5-tetramethylpyrrolidine-Noxyl-3-amino-4-

VIII- spin label group B 2,2,2,5-tetramethyl-1-pyrrolidine$\mathrm{N}$-oxyl-3-carboxilic

IX- spin label group B 2,2,2,5-tetramethylpyrrolidine-Noxyl-3-amino-4-

X-spin label group B 2,2,6,6-tetramethyppiperidine-N-oxyl4-amino-4-

XI- spin label group $B$ 3-amino- 2,2,2,5tetramethylpyrrolidine-1-oxyl
[1] G. Bacic, M. J. Nilges, R. L. Magin, T. Walczak, and H. M. Swartz, Magn. Reson. Med. 10, 266 (1989).

[2] J. A. Brivati, A. D. Stevens, and M. C. R. Symons, J. Magn. Reson. 92, 480 (1991)

[3] S. Lukiewicz, A. Sochanik, W. Subczynski, and J. Hyde, J. Invest. Dermatol. 87, 402 (1986).

[4] M. Calvin, H. H. Wang, G. Entine, D. Gill, P. Ferruti, M. A. Harpold, and M. P. Klein, Proc. Natl. Acad. Sci. USA, 63, 1 (1969).

[5] M. Schara, M. Sentjurc, L. Cotic, S. Pecar, B. Palcic, and C. Monti-Bragadin, Stud Biophys. 62, 141 (1977).

[6] M. Kveder, G. Pifat, S. Pecar, M. Schara, P. Ramos, and H. Esterbauer, Chem. Phys. Lipids 85, 1 (1997).

[7] P. F. M. Coesel and K. Waardernar, Algological Stud. 67, 69 (1994).

[8] J. W. Costerton, K. J. Cheng, G. G. Geesey, T. I. Ladd, J. C. Nichel, T. A. M. Dasgupta, and T. J. Marrie, Ann. Review Microbiol. 41, 435 (1987).

[9] W. Lange, Can. J. Microbiol. 22, 1181 (1976).

[10] C. S. Freire-Nordi, A. A. H. Vieira, and O. R. Nascimento, J. Phycol. 34, 631 (1998)

[11] C. S. Freire-Nordi, A. A. H. Vieira, and O. R. Nascimento, Phy- cologia, 42, 465 (2003)

[12] R. R. Guillard and C. J. Lorenzen. J. Phycol. 8, 10 (1972).

[13] R. Marchetto, S. Schreier, and C. R. Nakaie, J. Am. Chem. Soc. 115, 11042 (1993).

[14] C. R. Nakaie, S. Schreier, and A. C. M. Paiva, Biochim. Biophys. Acta 742, 63 (1983).

[15] V. N. Reinhold, Meth. Enzymol. 252, 44 (1972).

[16] B. S. Paulsen and A. A. H. Vieira, J. Phycol. 30. 638 (1994).

[17] O. H. Lowry and N. J. Rosebrough, A. L. Farr, and R. J. Randall, J. Biol. Chem. 193, 265 (1951).

[18] L. J. Berliner, Spin labelling. Theory and applications. (Academic Press, New York, 1976).

[19] B. Surek, P. Sengbush, Protoplasma, 108, 149 (1981).

[20] K. Chen and H. M. Swartz, Biochim. Biohys. Acta. 992, 131 (1989).

[21] K. Chen, J. F. Glockner, P. D. I. Morse, and H. M. Swartz, Biochemistry 28, 2496 (1989).

[22] E. C. Weaver and H. P. Chon, Science, 153, 301 (1966).

[23] J. Torres-Pereira, R. Mehlhorn, A. D. Keith, and L. Packer, Arch. Biochem. Biophys. 160, 90 (1974). 